Bin Yang, Ai Wang* and Yan Wang*

\title{
Crystal structure of poly[aqua-( $\mu_{2}-1,4-b i s(2 '-$ carboxylatophenoxy)benzene- $\left.\kappa^{2} 0: 0^{\prime}\right)-\left(\mu_{2}-4,4^{\prime}-\right.$ bipyridione- $\left.\mathrm{K}^{2} \mathrm{~N}: \mathrm{N}^{\prime}\right)$ cadmium(II)] monhydrate, $\mathrm{C}_{30} \mathrm{H}_{22} \mathrm{CdN}_{2} \mathrm{O}_{7} \cdot \mathrm{H}_{2} \mathrm{O}$
}

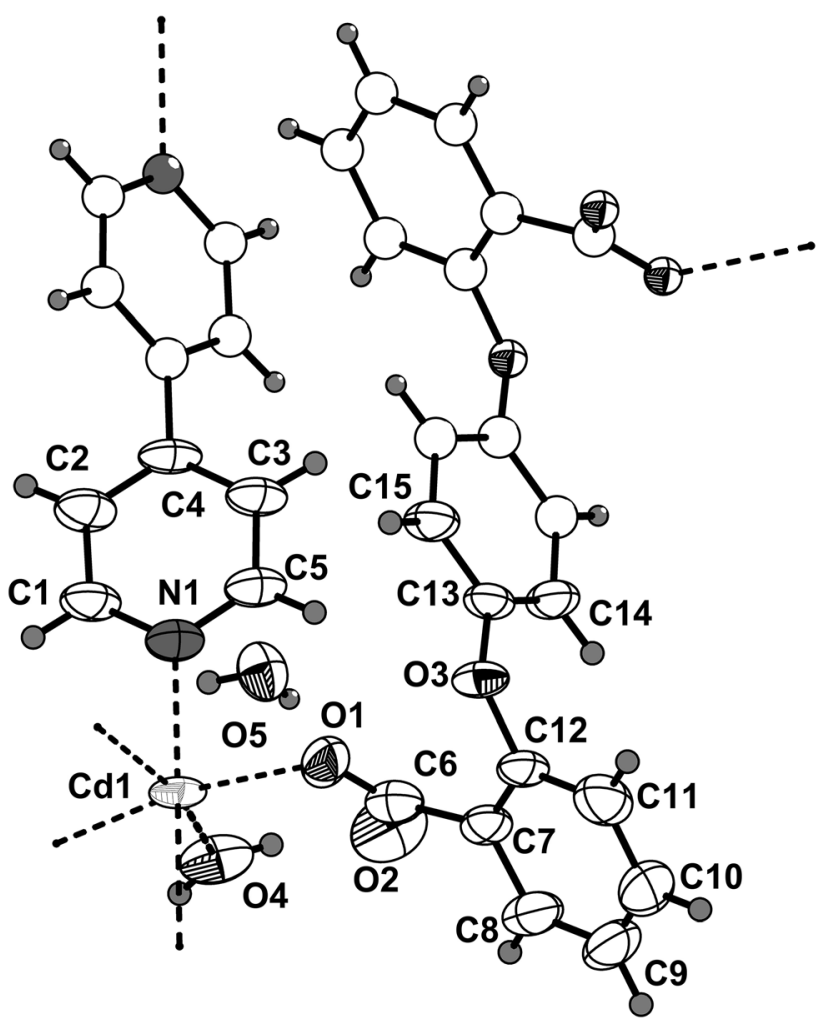

https://doi.org/10.1515/ncrs-2021-0036

Received January 20, 2021; accepted February 11, 2021; published online March 3, 2021

\section{Abstract}

$\mathrm{C}_{30} \mathrm{H}_{24} \mathrm{CdN}_{2} \mathrm{O}_{8}$, orthorhombic, Pccn (no. 56), $a=11.720(2) \AA$, $b=14.000(3) \AA, c=16.971(3) \AA, V=2784.7(10) \AA^{3}, Z=4$, $R_{g t}(F)=0.0544, \omega R_{r e f}\left(F^{2}\right)=0.1664, \mathrm{~T}=293(2) \mathrm{K}$.

*Corresponding authors: Ai Wang, Institute of Molecular Science, Key Laboratory of Chemical Biology and Molecular Engineering of the Education Ministry, Shanxi University, Wucheng Road 92, 030006 , Taiyuan, Shanxi, People's Republic of China,

E-mail: aiwang@sxu.edu.cn. https://orcid.org/0000-0002-30301539; and Yan Wang, Department of Chemistry \& Chemical Engineering, Luliang University, 033001, Luliang, People's Republic of China, E-mail: 12002@llhc.edu.cn

Bin Yang, School of Science of NUC, North University of China, 030051, Taiyuan, Shanxi, People's Republic of China,

E-mail: 1574481730@qq.com
CCDC no.: 2055252

Table 1 contains crystallographic data and Table 2 contains the list of the atoms including atomic coordinates and displacement parameters.

Table 1: Data collection and handling.

\begin{tabular}{ll}
\hline Crystal: & Colorless plate \\
Size: & $0.30 \times 0.25 \times 0.15 \mathrm{~mm}$ \\
Wavelength: & Mo $K \alpha$ radiation $(0.71073 \AA$ A $)$ \\
$\mu:$ & $0.84 \mathrm{~mm}^{-1}$ \\
Diffractometer, scan mode: & Bruker APEX-II, $\omega$ \\
$\theta_{\text {max }}$, completeness: & $25.6^{\circ},>99 \%$ \\
$N\left(h k l_{\text {measured }}, N(h k l)_{\text {unique }}, R_{\text {int }}:\right.$ & $6385,2586,0.047$ \\
Criterion for $I_{\text {obs }}, N(h k l)_{\text {gt }}:$ & $I_{\text {obs }}>2 \sigma\left(I_{\text {obs }}\right), 1834$ \\
$N(\text { param })_{\text {refined }}:$ & 200 \\
Programs: & Bruker [1], SHELX [2-4]
\end{tabular}

\section{Source of material}

All chemicals were of analytical reagent grade and used without further purification. A mixture of $\mathrm{Cd}\left(\mathrm{NO}_{3}\right)_{2} \cdot 4 \mathrm{H}_{2} \mathrm{O}$ (30.8 mg, $0.1 \mathrm{mmol}), \mathrm{H}_{2} \mathrm{bcpb}(17.5 \mathrm{mg}, 0.05 \mathrm{mmol}$ ), 4,4-bipy(15.6 mg, $0.1 \mathrm{mmol}), \mathrm{H}_{2} \mathrm{O}(6.0 \mathrm{~mL})$ and $\mathrm{NaOH}(0.5 \mathrm{~mL}$ $0.25 \mathrm{~mol} / \mathrm{L}$ ) was placed in a $25 \mathrm{~mL}$ of Teflon-lined stainless steel vessel, which was heated at $140^{\circ} \mathrm{C}$ for three days. Followed by slow cooling to room temperature, colorless plate crystals of title compound were obtained in $55.7 \%$ yield.

\section{Experimental details}

Multi-scan program SADABS [1] was used for absorption correction. The structures were solved by direct methods and refined using SHELXS-97 [2, 3] and SHELXL-2014/7 [4]. Hydrogen atoms attached to $\mathrm{C}$ atoms were placed geometrically and refined using a riding model approximation, with $\mathrm{C}-\mathrm{H}=0.96 \AA$ and $U_{\text {iso }}(\mathrm{H})=1.2 U_{\text {eq }}(\mathrm{C})$. 
Table 2: Fractional atomic coordinates and isotropic or equivalent isotropic displacement parameters $\left(\AA^{2}\right)$.

\begin{tabular}{|c|c|c|c|c|}
\hline Atom & $x$ & $y$ & $z$ & $U_{\text {iso }} * / U_{\text {eq }}$ \\
\hline Cd1 & 0.2500 & 0.7500 & $0.29086(3)$ & $0.0461(2)$ \\
\hline 01 & $0.2441(3)$ & $0.6338(3)$ & $0.3837(4)$ & $0.0712(14)$ \\
\hline 02 & $0.2364(5)$ & $0.5334(7)$ & $0.2883(3)$ & 0.121 (3) \\
\hline 03 & $0.2694(3)$ & $0.5282(3)$ & $0.5278(2)$ & $0.0545(10)$ \\
\hline $04^{\mathrm{a}}$ & $0.2514(8)$ & $0.6683(10)$ & $0.1768(6)$ & $0.090(3)$ \\
\hline $\mathrm{H} 4 \mathrm{~A}^{\mathrm{a}}$ & $0.234(14)$ & $0.689(5)$ & 0.1316 (19) & $0.135^{*}$ \\
\hline$H 4 B^{a}$ & $0.278(15)$ & $0.612(5)$ & 0.177 (3) & $0.135^{*}$ \\
\hline N1 & $0.4479(5)$ & $0.7490(3)$ & $0.2892(3)$ & 0.0535 (13) \\
\hline C1 & 0.5075 & $0.8231(5)$ & $0.2596(4)$ & $0.0607(16)$ \\
\hline $\mathrm{H} 1$ & 0.4674 & 0.8748 & 0.2390 & $0.073^{*}$ \\
\hline $\mathrm{C} 2$ & $0.6260(4)$ & $0.8259(5)$ & $0.2583(4)$ & $0.0614(17)$ \\
\hline $\mathrm{H} 2$ & 0.6639 & 0.8785 & 0.2374 & $0.074^{\star}$ \\
\hline C3 & $0.6253(4)$ & $0.6734(5)$ & $0.3183(4)$ & 0.0574 (15) \\
\hline $\mathrm{H} 3$ & 0.6632 & 0.6204 & 0.3384 & $0.069^{*}$ \\
\hline $\mathrm{C} 5$ & $0.5079(4)$ & $0.6763(5)$ & $0.3184(3)$ & 0.0570 (15) \\
\hline H5 & 0.4684 & 0.6249 & 0.3398 & $0.068^{\star}$ \\
\hline $\mathrm{C} 6$ & $0.2220(5)$ & $0.5533(5)$ & $0.3563(4)$ & 0.0587 (15) \\
\hline $\mathrm{C} 7$ & $0.1672(4)$ & $0.4802(4)$ & $0.4101(3)$ & $0.0487(12)$ \\
\hline $\mathrm{C} 8$ & $0.0833(5)$ & $0.4219(5)$ & $0.3767(4)$ & $0.0657(17)$ \\
\hline $\mathrm{H} 8$ & 0.0691 & 0.4256 & 0.3229 & 0.079 * \\
\hline C9 & $0.0215(6)$ & $0.3592(5)$ & $0.4223(6)$ & $0.079(2)$ \\
\hline H9 & -0.0351 & 0.3217 & 0.3995 & $0.095^{*}$ \\
\hline C10 & $0.0433(6)$ & $0.3523(5)$ & $0.5000(6)$ & 0.089 (3) \\
\hline $\mathrm{H} 10$ & 0.0017 & 0.3096 & 0.5306 & $0.106^{*}$ \\
\hline C11 & $0.1265(6)$ & $0.4079(6)$ & $0.5347(4)$ & $0.075(2)$ \\
\hline H11 & 0.1410 & 0.4028 & 0.5884 & $0.091^{*}$ \\
\hline $\mathrm{C} 12$ & $0.1886(4)$ & $0.4716(4)$ & $0.4887(3)$ & $0.0502(13)$ \\
\hline C13 & $0.3845(4)$ & $0.5112(4)$ & $0.5111(3)$ & $0.0465(12)$ \\
\hline C14 & $0.4242(4)$ & $0.4313(4)$ & 0.4724 (3) & $0.0543(14)$ \\
\hline H14 & 0.3736 & 0.3850 & 0.4545 & $0.065^{*}$ \\
\hline C15 & $0.4595(4)$ & $0.5791(4)$ & 0.5394 (3) & 0.0551 (15) \\
\hline $\mathrm{H} 15$ & 0.4318 & 0.6320 & 0.5664 & $0.066^{*}$ \\
\hline C4 & $0.6868(5)$ & $0.7495(5)$ & $0.2883(3)$ & 0.0520 (15) \\
\hline 05 & 0.2500 & 0.7500 & 0.5239 (4) & $0.069(2)$ \\
\hline $\mathrm{H} 5 \mathrm{~A}$ & $0.255(7)$ & $0.791(5)$ & 0.487 (4) & $0.104^{\star}$ \\
\hline
\end{tabular}

${ }^{a}$ Occupancy: 0.5 .

Hydrogen atoms attached to $\mathrm{O}$ atoms were located from difference Fourier maps and refined using $U_{\text {iso }}(\mathrm{H})=1.5$ $U_{\text {eq }}(\mathrm{O})$.

\section{Comment}

In the past few decades, ether bond polycarboxylic coordination polymers (CPs) with structural and functional tenability [5] have attracted considerable attention from both academia and industry on account of their exploitable properties for potential application in areas such as separation [6], catalysis [7], ion exchange [8, 9], chirality, magnetism [10] luminescence [11], and nonlinear optics. We recently studied the self-assembly reaction of 1,4-bis(2'-carboxylatophenoxy)benzene $\left(\mathrm{H}_{2} \mathrm{bcpb}\right)$ and metal ions. Herein, we report a cadmium(II) compound with two-dimensional structure, namely $\left[\mathrm{Cd}\left(\mu_{2^{-}}\right.\right.$ bcpb)(4,4-bipy) $\left.\left(\mathrm{H}_{2} \mathrm{O}\right), \mathrm{H}_{2} \mathrm{O}\right]_{n}\left(\mathrm{bcpb}^{2-}=\right.$ deprotonated 1,4-bis(2'-carboxylatophenoxy)benzene; 4,4-bipy = 4,4-bipyridine).

Single-crystal X-ray analysis shows that the compound crystallizes in the orthorhombic space group Pccn with a 2D structure. The asymmetric unit contains one half of a Cd(II) cation, one half of a bcpb ${ }^{2-}$ anion, one half of a 4,4-bipy, one half of a coordinated water molecule and one half of a free water molecule. The $\mathrm{Cd} 1$ atom is sixcoordinated and forms a slightly distorted octahedron geometry, which is completed by two carboxylate $\mathrm{O}$ donors coming from two $\mathrm{bcpb}^{2-}$ moieties, two $\mathrm{N}$ donors from 4,4-bipy ligand and two $\mathrm{O}$ atoms from two water molecules. The bond lengths of the $\mathrm{Cd}-\mathrm{O}$ bonds are in the range of 2.247(10)-2.266(5) $\AA$, and the distance of the $\mathrm{Cd}-\mathrm{N}$ bond is 2.320(6) $\AA$. The $\mathrm{O}-\mathrm{Cd}-\mathrm{O}$ angles are within the range of $61.2(7)-164.5(4)^{\circ}$. The bcpb ${ }^{2-}$ ligand connects two $\mathrm{Cd}(\mathrm{II})$ ions with a $\mu_{2}-\mathrm{k}^{2} \mathrm{O}^{1}: \mathrm{O}^{1}$-coordination mode. In the crystal, intermolecular $\mathrm{O}-\mathrm{H} \cdots \mathrm{O}$ hydrogen bonds involving the carboxylate oxygen atoms and lattice water molecules link the moiteties into a three-dimensional network. The free water molecule and $\mathrm{bcpb}^{2-}$ ligand were linked together through $\mathrm{O} 5-\mathrm{H} 5 \mathrm{~A} \cdots \mathrm{O} 3^{\mathrm{ii}}$ and $\mathrm{O} 5-\mathrm{H} 5 \mathrm{~A} \cdots \mathrm{O} 1^{\mathrm{ii}}$ (Symmetry codes: (ii) $-x+1 / 2,-y+3 / 2, z$ ) hydrogen bonds. Additionally, short $\pi \cdots \pi$ interactions between $\operatorname{Cg} 1$ and $\operatorname{Cg} 1^{\mathrm{i}}$ occur in the structure (Symmetry codes: (i) $-x, 1-y, 1-z$ ). $\operatorname{Cg} 1$ ring is composed of $\mathrm{C} 7-\mathrm{C} 12$. The geometry analysis shows a face-to-face alignment of the aromatic-aromatic rings. The distance between $\mathrm{Cg} 1$ ring and $\mathrm{Cg}^{\mathrm{v}}$ ring is 3.738(4) $\AA$.

Author contributions: All the authors have accepted responsibility for the entire content of this submitted manuscript and approved submission.

Research funding: Science and Technology Project of $\mathrm{Lu}$ Liang City (Grant No. GXZDYF2019083); NSFC (Grant Nos. 21671124 \& 21571118); Scientific and Technological Innovation Project of the Higher Education Institutions of Shanxi Province, STIP (Grant No. 2019L0086); Natural Science Foundation of Shanxi Province (Grant No. 201901D211145).

Conflict of interest statement: The authors declare no conflicts of interest regarding this article.

\section{References}

1. Bruker. SMART, SAINT and SADABS; Bruker AXS Inc.: Madison, Wisconsin, USA, 1998. 
2. Sheldrick G. M. SHELXTL - integrated space-group and crystalstructure determination. Acta Crystallogr. 2015, A71, 3-8.

3. Sheldrick G. M. A short history of SHELXTL. Acta Crystallogr. 2008, A64, 112-122.

4. Sheldrick G. M. Crystal structure refinement with SHELXL. Acta Crystallogr. 2015, C71, 3-8.

5. Yaghi O. M., O’Keeffe M., Ockwig N. W., Chae H. K., Eddaoudi M., Kim J. Reticular synthesis and the design of new materials. Nature 2003, 423, 705-714.

6. Blatov V. A., Shevchenko A. P., Proserpio D. M. Applied topological analysis of crystal structures with the program package Topspro. Cryst. Growth Des. 2014, 14, 3576-3586.

7. Manna K., Zhang T., Greene F. X., Lin W. Bipyridine- and phenanthroline-based metal-organic frameworks for highly efficient and tandem catalytic organic transformations via directed C-H-activation. J. Am. Chem. Soc. 2015, 137, 2665-2673.
8. Lv L. L., Yang J., Zhang H. M., Liu Y. Y., Ma J. F. Metal-ion exchange, small-molecule sensing, selective dye adsorption, and reversible lodine uptake of three coordination polymers constructed by a new Resorcin[4] arene-based tetracarboxylate. Inorg. Chem. 2015, 54, 1744-1755.

9. Wu H., Yang J., Su Z. M., Batten S. R., Ma J. F. An exceptional 54-fold interpenetrated coordination polymer with 103-srs network topology. J. Am. Chem. Soc. 2011, 133, 11406-11409.

10. Goswami S., Leitus G., Tripuramallu B. K., Goldberg I. Mn" and Co" coordination polymers showing field-dependent magnetism and slow magnetic relaxation behavior. Cryst. Growth Des. 2017, 17, 4393-4404.

11. Xu J., Su W., Hong M. A series of lanthanide secondary building units based metal-organic frameworks constructed by organic pyridine-2,6-dicarboxylate and inorganic sulfate. Cryst. Growth Des. 2011, 11, 337-346. 